\title{
Adesivos à base de cianoacrilato para síntese de tecido mole*
}

\section{Cyanoacrylate adhesives for the synthesis of soft tissue}

\author{
Sybele Saska ${ }^{1}$ \\ Eduardo Hochuli-Vieira ${ }^{3}$
}

Ana Maria Minarelli Gaspar ${ }^{2}$

Resumo: Fundamentos - Adesivos teciduais têm sido muito usados para síntese de ferida, em função de ser um método indolor, rápido e de fácil execução.

Oвјетіvos - Analisar e comparar compatibilidade dos adesivos, etil-cianoacrilato (Super Bonder) e butilcianoacrilato (Histoacryl), e a reparação de incisões em dorso de ratos entre o fio de sutura e os respectivos adesivos.

MÉTodos - Foram usados 15 ratos. Realizaram-se duas lojas cirúrgicas no dorso. Em cada uma, foi implantado um tubo de polietileno $(10 \mathrm{~mm} \times 1 \mathrm{~mm})$, os quais foram preenchidos com os adesivos Super Bonder (lado direito) e Histoacryl (lado esquerdo). As incisões, do lado esquerdo, foram coaptadas com Super Bonder, e as do lado direito, com Histoacryl. Uma incisão mediana, entre as duas incisões, foi realizada e suturada com fio de seda. Os animais foram mortos, depois de 7(sete), 35(trinta) e 120 (cento e vinte dia) dias.

RESUlTADOs: Os adesivos usados, no presente estudo, não promoveram reação inflamatória, quando usados para síntese das incisões. Porém, estes adesivos, quando implantados no subcutâneo, promoveram reação inflamatória até 120 (cento e vinte dia) dias, no entanto, a reação é mais intensa com Histoacryl. Conclusões: Super Bonder e Histoacryl permitem o processo cicatricial dos tecidos incisados; facilitam a sutura das incisões. Desta forma, estes podem ser utilizados para sínteses de feridas, lacerações ou incisões cutâneas.

Palavras-chave: Adesivos teciduais; Cianoacrilatos; Hemostáticos; Técnicas de sutura; Teste de materiais; Ratos

Abstract: BaCKGROUND: Tissue adhesives have been used for the synthesis of wound due to their painless application and quick and easy handling.

OвJеCтіves: The purpose of this study was to analyze and compare the compatibility of the adhesives ethylcyanoacrylate (Super Bonder) and butyl-cyanoacrylate (Histoacryl), and to compare the reparation of incisions in the dorsum of rats with suture and the respective adhesives.

Methods: Fifteen rats were used. Two surgical pockets were created in their dorsum. A polyethylene tube $(10 \mathrm{~mm} \times 1 \mathrm{~mm})$ was implanted in each one. Each tube was filled with the adhesives Super Bonder (left side) and Histoacryl (right side). The incisions on the left side were closed with Super Bonder, and the incisions on the right side, with Histoacryl. A median incision between the two other incisions was made and closed with braided silk suture. The animals were killed after, 7, 35 and 120 days.

RESULTS: The adhesives used in the present study did not promote inflammatory reaction when used for the synthesis of incisions. However, when implanted subcutaneously, they caused an inflammatory reaction within 120 days. Reaction is more severe with Histoacryl.

Conclusions: Super Bonder and Histoacryl can be used effectively in the healing of incised tissues; they aid in the suture of incisions. However, these adhesives can be used for the synthesis of wounds, lacerations or cutaneous incisions.

Keywords: Cyanoacrylates; Hemostatics; Materials testing; Rats; Suture techniques; Ttissue adhesives

Recebido em 26.01.2009.

Aprovado pelo Conselho Consultivo e aceito para publicação em 26.09.2009.

* Trabalho realizado nos Departamentos de Morfologia e de Diagnóstico e Cirurgia da Faculdade de Odontologia de Araraquara - Universidade Estadual Paulista (UNESP) São Paulo (SP), Brasil.

Conflito de interesse: Nenhum / Conflict of interest: None

Suporte financeiro: Nenhum / Financial funding: None

1 Cirurgiã-dentista, aluna de Mestrado em Biotecnologia - Instituto de Química de Araraquara - Universidade Estadual Paulista (UNESP) - São Paulo (SP), Brasil Profa. Dra. Assistente de Anatomia - Departamento de Morfologia da Faculdade de Odontologia de Araraquara - Universidade Estadual Paulista (UNESP) - São Paulo (SP), Brasil.

Prof. Dr. Assistente de Cirurgia e Traumatologia Buco-Maxilo-Facial - Departamento de Diagnóstico e Cirurgia da Faculdade de Odontologia de Araraquara Universidade Estadual Paulista (UNESP) - São Paulo (SP), Brasil

(C) 2009 by Anais Brasileiros de Dermatologia

An Bras Dermatol. 2009;84(6):585-92. 


\section{INTRODUÇÃO}

O uso de adesivos teciduais para aplicação, em síntese de tecidos moles, principalmente, em áreas de difícil acesso, tem se tornado uma prática comum, em procedimentos cirúrgicos. Estes adesivos são bastante utilizados para fechamento de ferida, principalmente, em crianças, pelo fato de ser um método indolor, rápido, de fácil execução, e proporcionam mínima cicatriz, salvo algumas complicações. Os fechamentos das feridas com técnicas de suturas convencionais, em sua totalidade, apresentam um maior índice de falhas, comparando-se com fechamento, nos quais são usados adesivos. ${ }^{1}$

Estes adesivos são excelentes agentes hemostáticos para promover hemostasia de vasos periféricos. ${ }^{2-8}$ Outra função dos adesivos teciduais é promover um selamento tecidual, prevenindo o extravasamento de fluídos linfáticos, por exemplo, os adesivos à base de cianoacrilatos, os quais são impermeáveis e não requerem que as feridas sejam revistas, ao se reaproximarem. ${ }^{9}$

Os alquil-2-cianoacrilatos foram primeiramente sintetizados, em 1949, por Ardis, ${ }^{10}$ mas, somente em 1959, suas propriedades adesivas foram relatas por Coover. ${ }^{11} \mathrm{O}$ grupo destes adesivos possui diferentes tipos de cianoacrilato, alterando somente o comprimento da cadeia lateral, como: metil $\left(\mathrm{R}=\mathrm{CH}_{3}\right)$, etil $\left(\mathrm{R}=\mathrm{C}_{2} \mathrm{H}_{5}\right)$, butil e isobutil $\left(\mathrm{R}=\mathrm{C}_{4} \mathrm{H}_{9}\right)$ e octil-cianoacrilato $\left(\mathrm{R}=\mathrm{C}_{8} \mathrm{H}_{17}\right) \cdot{ }^{12} \mathrm{Os}$ cianoacrilatos se polimerizam em poucos segundos, quando entram em contato com água e superfícies, tais como: endotélio, mucosa, pele, sangue e osso, degradando-se em cianoacetato e formaldeído, com uma ligeira reação exotérmica. Por serem de forma líquida, possuem a habilidade de penetrar em superfícies irregulares dos tecidos, promovendo uma forte adesão. ${ }^{8,13,14} \mathrm{~A}$ toxicidade destes adesivos está relacionada a sua velocidade de degradação, e ao tamanho da cadeia, ou seja, quanto maior for a cadeia lateral, menor a velocidade de degradação e menor a histotoxicidade, e também, quanto maior a cadeia lateral maior tempo de cura. ${ }^{13,14}$

Vários autores ao longo dos anos analisaram a biocompatibilidade dos adesivos de cianoacrilato, ${ }^{14,15}$ e observaram que o metil-cianoacrilato é o que apresenta o maior grau de histotoxicidade, causando edema e necrose tecidual, sendo contraindicados para o uso clínico. ${ }^{16}$ Adesivos de etil-cianoacrilato não apresentaram reação inflamatória, apesar de apresentarem uma maior velocidade de degradação. 4, 17, 18

O emprego de n-butil-2-cianoacrilato, um dos adesivos mais estudados e usados em cirurgias faciais e bucais, em humanos, 3, 7, 19-22 e em cirurgias faciais e em dorso de animais, ${ }^{5,23,24}$ promove uma cicatrização mais rápida, sem complicações em relação às suturas convencionais, uma vez que reduz o tempo cirúrgico e elimina a necessidade de remoção de sutura, no pós-operatório. Além disso, possui efeito bacteriostático e efeito hemostático melhor do que a sutura. Ellis e Shakick ${ }^{20}$ concluíram que o Histoacryl ${ }^{\circledR}$ é um adesivo de tecido ideal para fechamento de superfície cutânea, em relação à segurança, confiabilidade, efetividade de resistência à tração e custo.

$\mathrm{O}$ adesivo etil-cianoacrilato, enquanto foi utilizado em síntese de feridas, em humanos, apresentou resultados satisfatórios, sem efeitos adversos ou complicações cosméticas e hemóstase imediata, se for comparado com a técnica convencional de sutura. ${ }^{17,25}$ No dorso de animais, o etil-cianoacrilato também promoveu hemostasia imediata, simplificou e abreviou o procedimento operatório, não interferindo no processo de reparo, não ocorrendo, assim, supuração, necrose tecidual ou retração das margens da ferida, nas áreas operadas, em relação ao fio de sutura. ${ }^{26}$

Desta forma, o objetivo deste trabalho foi analisar a biocompatibilidade dos adesivos à base de cianoacrilatos como: etil-cianoacrilato (Super Bonder ${ }^{\circledR}$ ) e n-butil-2-cianoacrilato (Histoacryl ${ }^{\circledR}$ ), e comparar, histologicamente, a reparação tecidual de incisões em dorso de ratos entre o fio de sutura e os adesivos Super Bonder ${ }^{\circledR}$ e Histoacryl ${ }^{\circledR}$.

\section{MATERIAIS E MÉTODOS}

A amostra constituiu-se de 15 ratos Rattus Norvegicus Holtzman, machos, pesando em média 200 (duzentos) gramas. Os animais foram anestesiados com administração intramuscular de cloridrato de ketamina $(25 \mathrm{mg} / \mathrm{kg})$ e de cloridrato de xilazina $(5 \mathrm{mg} / \mathrm{kg})$. Após tricotomia e assepsia da região dorsal, realizaram-se três incisões, com distância de $2 \mathrm{~cm}$ entre elas, em sentido longitudinal com relação ao corpo do animal, de aproximadamente $2 \mathrm{~cm}$. O protocolo da experimentação animal foi aprovado pelo Comitê de Ética, na Experimentação Animal da Faculdade de Odontologia de Araraquara- UNESP.

Antes da coaptação das incisões, o tecido conjuntivo foi divulsionado lateralmente, com auxílio de uma tesoura de ponta romba, formando lojas cirúrgicas, com distância de aproximadamente $3 \mathrm{~cm}$ das incisões já realizadas e com uma distância entre as lojas de aproximadamente $3 \mathrm{~cm}$. Duas lojas cirúrgicas foram confeccionadas: uma do lado esquerdo e outra do lado direito, onde se implantou, em cada loja, um tubo de polietileno (Kit Delton - Dentsply), de $10 \mathrm{~mm}$ de comprimento e $1 \mathrm{~mm}$ de diâmetro interno (Figura 1A), com uma de suas extremidades fechadas, à quente, utilizando uma pinça aquecida. Estes tubos foram esterilizados em autoclave. As paredes laterais de cada do tubo de polietileno serviram de controle positivo, grupo controle. Preencheram-se os tubos, com auxílio 
de uma seringa de insulina, com os respectivos materiais experimentais:

Grupo A: etil-cianoacrilato (Super Bonder ${ }^{\circledR}$, Loctite - Brasil).

Grupo B: butil-cianoacrilato (Histoacryl ${ }^{\circledR}$, B Braun - Alemanha).

Após o preenchimento dos tubos com os adesivos, aplicou-se soro fisiológico 0,9\% estéril, nas extremidades dos tubos, para ocorrer a polimerização do material, antes da implantação nas lojas cirúrgicas. Após este procedimento, os tubos, com materiais experimentais, foram cuidadosamente introduzidos, nas lojas cirúrgicas, mantendo-se a posição paralela à incisão central. O material experimental do grupo A foi introduzido na loja cirúrgica do lado esquerdo, o material experimental do grupo $\mathrm{B}$ foi introduzido na loja cirúrgica do lado direito.

Em seguida, as incisões, do lado esquerdo (grupo I), foram aproximadas e foi aplicado o adesivo Super Bonder ${ }^{\circledR}$, as incisões medianas (grupo II), foram suturadas com fio de seda 4-0 (Ethicon Johnson \& Johnson, Brasil) e do lado direito (grupo III), as incisões foram aproximadas com adesivo Histoacryl $^{\circledR}$ (Figura 1B).

Decorridos os períodos 7, 30 e 120 dias, após a cirurgia, os animais foram novamente anestesiados, seguindo o protocolo descrito acima e tricotomizados, na região dorsal. As áreas das incisões e dos implantes foram cirurgicamente removidas. Em segui$\mathrm{da}$, os animais foram eutanasiados, com uma superdosagem do mesmo anestésico empregado. As peças foram fixadas em solução de Bouin, por 48 horas, e processadas segundo técnica rotineira para inclusão em parafina, onde foram realizados cortes semisseriados, de $6 \mathrm{~mm}$, no sentido transversal da pele e, posteriormente, corados em hematoxilina-eosina.

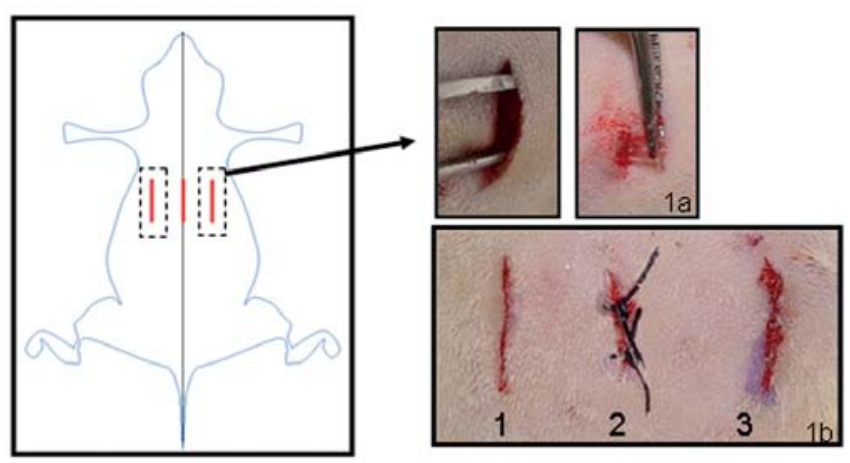

Figura 1: A. Divulsão para confecção da loja cirúrgica; introdução do tubo de polietileno na loja cirúrgica. Lado direito, tubo com Super Bonder ${ }^{\circledR}$ e lado esquerdo, tubo com Histoacryl ${ }^{\circledR}$. B. Incisões coaptadas com Super Bonder ${ }^{\circledR}$ (1), fio de seda (2) e Histoacryl ${ }^{\circledR}$ (3).

\section{RESULTADOS}

\section{Grupo A - Super Bonder ${ }^{\circledR}$}

No período de 7 dias, observou-se intenso infiltrado inflamatório, na extremidade do tubo, onde o tecido conjuntivo teve contato direto com o adesivo, já nas laterais e na outra extremidade do tubo, observou-se moderada reação inflamatória com células mono e polimorfonucleares. A cápsula, formada por tecido conjuntivo denso, adjacente à parede dos tubos; tecido conjuntivo frouxo, próximo aos implantes em organização; estase sanguínea, material remanescente, e adjacente ao adesivo e ao tubo, células gigantes - tipo corpo estranho (Figura 2A e 2B). Aos 30 dias, leve infiltrado inflamatório, com presença de macrófagos e células gigantes tipo corpo estranho, próximos ao adesivo remanescente e ao tubo; estase sanguínea (Figura 2C e 2D). Aos 120 dias, ainda observou-se moderado infiltrado inflamatório, contendo, principalmente, monócitos, linfócitos e presença de, em menor proporção, basófilos, e poucas células gigantes, no tecido adjacente ao adesivo remanescente, e ao tubo de polietileno (Figura 2E e 2F).

\section{Grupo B - Histoacryl ${ }^{\circledR}$}

Aos 7 dias, neste grupo, observou-se moderado infiltrado inflamatório, com predomínio de monócitos e linfócitos, na extremidade do tubo adjacente ao adesivo, e estase sanguínea. Adjacente ao material remanescente e as laterais dos tubos, há presença de células gigantes (Figura 3A e 3B). Aos 30 dias, moderado infiltrado inflamatório com vasoconstrição, semelhante ao grupo A (Figura 3C). Após 120 dias, o infiltrado inflamatório passou de moderado a leve, com células mononucleares (linfócitos e monócitos) e poucos basófilos; presença de poucas células gigantes, no tecido adjacente ao adesivo remanescente. Observouse uma maior quantidade de material remanescente, ao ser comparado com o grupo A (Figura 3D). Na lateral do tubo de polietileno, também se observa presença de células gigantes, junto ao infiltrado inflamatório adjacente, ao tubo aos 30 dias (Figura 3E), e no período de 120 dias, ainda há presença de células gigantes, tipo corpo estranho, e leve infiltrado inflamatório, no tecido conjuntivo fibroso adjacente ao tubo de polietileno (Figura 3F).

\section{Grupo I - Super Bonder ${ }^{\circledR}$}

Aos 7 dias, o epitélio estratificado pavimentoso queratinizado apresentou-se em reorganização, com ausência de solução de continuidade na superfície, presença de tecido necrótico, acima da incisão. O tecido conjuntivo subjacente se apresentou desorganizado, com poucas células inflamatórias e fibras colágenas, com grande atividade fibroblástica (tecido conjuntivo frouxo). Houve presença de material remanes- 

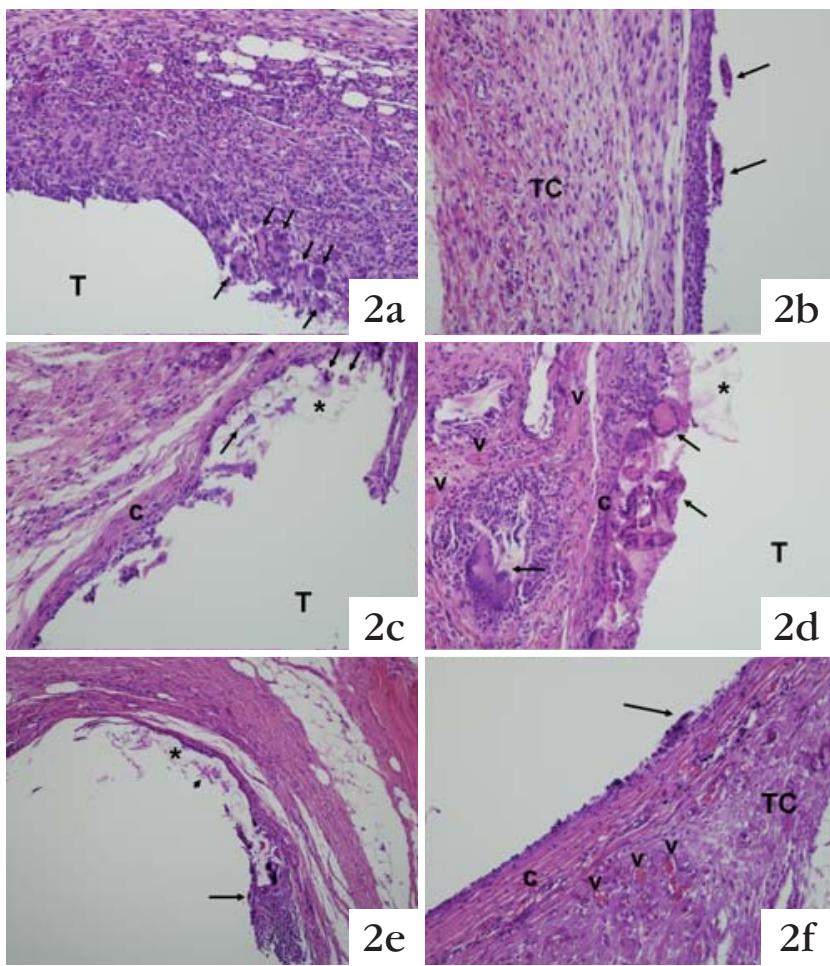

Figura 2: Grupo A: A. 7 dias - adjacente ao tubo (T) infiltrado inflamatório e células gigantes, tipo corpo estranho (setas); estase sanguínea. H.E. 200x; B. 7 dias - na lateral do tubo (T) infiltrado inflamatório e células gigantes tipo corpo estranho (setas); formação de cápsula, tecido conjuntivo frouxo (TC), estase sanguínea. H.E. 200x; C. 30 dias - formação de cápsula (c) ao redor do tubo (T), leve infiltrado inflamatório, macrófagos (setas), material remanescente (*). H.E. 200x; D. 30 dias - formação de cápsula (c) ao redor do tubo (T), presença de células inflamatórias adjacentes ao material remanescente $(*)$, células gigantes tipo corpo estranho (setas), estase sanguínea (v). H.E. 200x; E. 120 dias - moderado infiltrado inflamatório (seta) somente adjacente ao material (*), macrófagos (seta menor). H.E. 100x; F. 120 dias - nas laterais do tubo, presença de cápsula mais densa que nos períodos anteriores e célula gigante tipo corpo estranho (setas). H.E. 200x
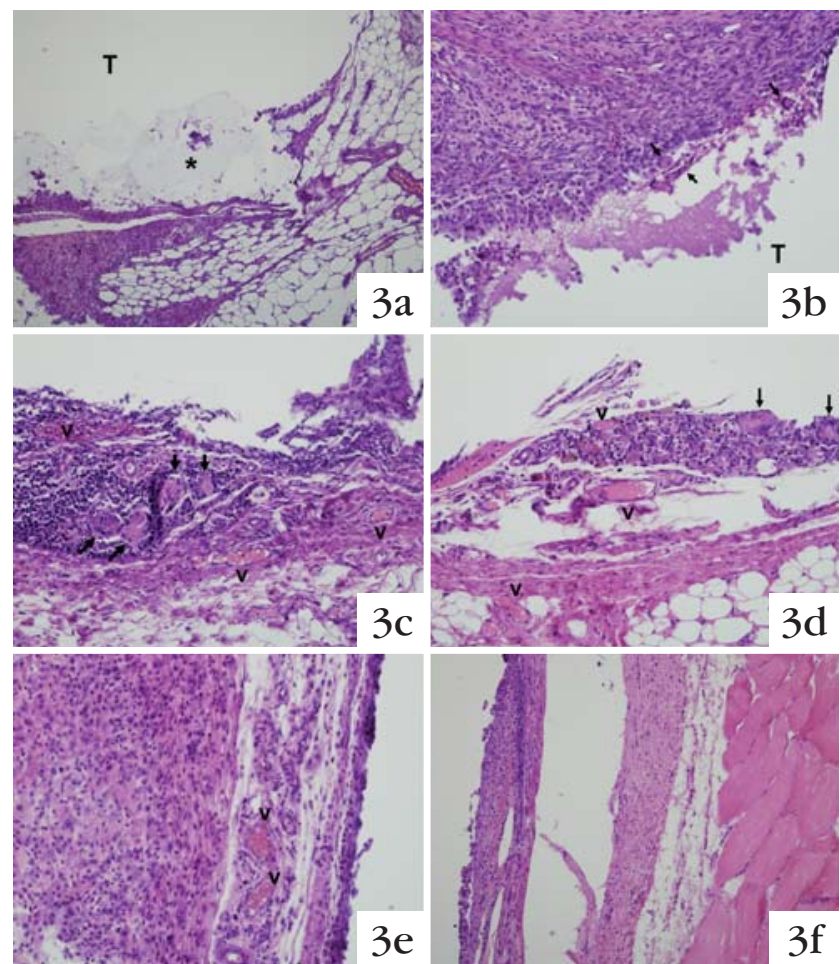

FigurA 3: Grupo B: A. 7 dias - presença de material remanescente (*), na extremidade do tubo, (T) e infiltrado inflamatório moderado adjacente ao material (I). H.E. 100x; B. 7 dias - o tecido conjuntivo adjacente ao material apresenta células inflamatórias e células gigantes tipo corpo estranho (setas). H.E. 200x; C. 30 dias - células gigantes, junto ao infiltrado inflamatório adjacente ao material (setas), estase sanguínea (v). H.E. 200x; D. 120 dias - células gigantes, junto ao moderado infiltrado inflamatório adjacente ao material (setas), estase sanguínea (v), semelhante ao período de 30 dias. H.E. 200x; E. 7 dias - na lateral do tubo também se observa presença de células gigantes, junto ao infiltrado inflamatório (setas); estase sanguínea (v). H.E. 200x; F. 120 dias - observa-se, na lateral do tubo, a presença de células gigantes junto à cápsula fibrosa com leve infiltrado inflamatório (setas). H.E. 100x cente englobado pelo tecido conjuntivo (Figura 4A). No período de 30 dias, observou-se que o tecido epitelial estava reparado, apresentando solução de continuidade, com presença de células querato-hialínicas, e o tecido conjuntivo reparado apresentou-se com maior número de feixes espessos de fibras colágenas não-modelado, com características de normalidade. Ausência de material remanescente e de células inflamatórias (Figura 4B). Aos 120 dias, observaram-se características de tecido normal, com fibras colágenas densas e organizadas entre si, mais paralelamente, vasos capilares, ductos glandulares e folículos pilosos (Figura 4C).

\section{Grupo II - Sutura fio de seda 4-0}

No período de 7 dias, o epitélio não apresentou superfície de continuidade, sendo que o tecido con- juntivo subjacente estava em fase de organização; tecido necrótico e coágulo sanguíneo, no local da ferida; reação inflamatória de leve a moderada, no tecido conjuntivo subjacente, foi observada nos espécimes (Figura 5A). Aos 30 dias, a cicatrização está completa com o epitélio íntegro, contínuo com a superfície; observam-se células querato-hialínicas na superfície, e o tecido conjuntivo fibroso, com características de normalidade (Figura 5B). Após os 120 dias, tecido conjuntivo fibroso, com características de normalidade, com inúmeros ductos glandulares, folículos pilosos e capilares (Figura 5C).

\section{Grupo III- Histoacryl ${ }^{\circledR}$}

Os espécimes apresentaram características histológicas semelhantes aos grupos descritos anteriormente. Aos 7 dias, o epitélio estratificado pavimento- 

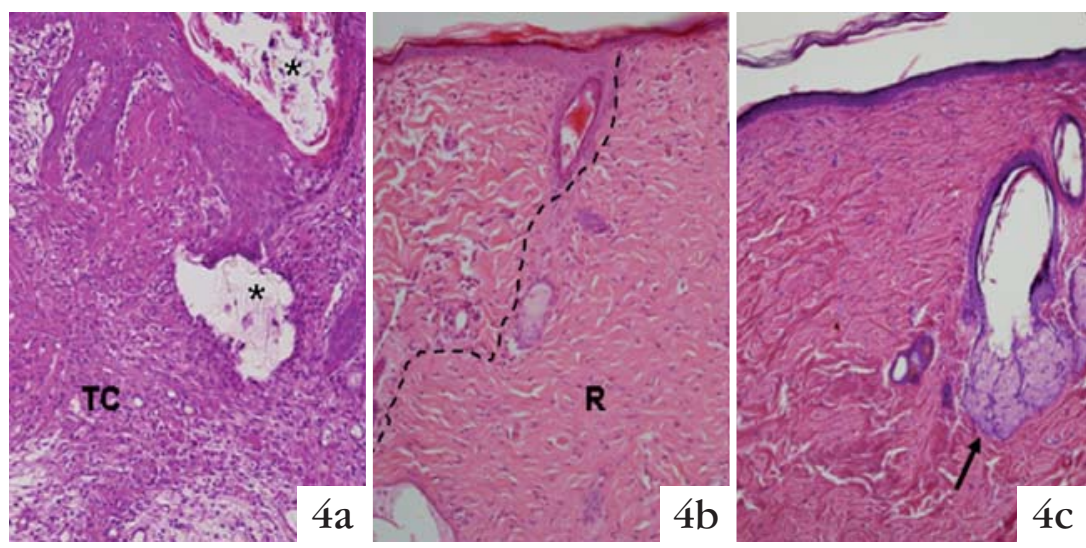

Figura 4: Grupo I: A. 7 dias - tecido conjuntivo frouxo em organização (TC), com poucas células inflamatórias e fibras colágenas, com grande atividade fibroblástica e presença de material remanescente $(*)$.H.E. 200x; B. 30 dias - tecido epitelial reparado apresentando solução de continuidade com presença de células querato-hialínicas (seta). No local da incisão, tecido conjuntivo denso fibroso, com maior quantidade de fibras colágenas densas (R) e com uma orientação definida, em relação ao tecido conjuntivo adjacente (tracejado); apresentando-se organizado com características de normalidade (R). H.E. 200x; C. 120 dias tecido conjuntivo totalmente reparado, apresentando-se denso e fibroso, com presença de glândulas (seta). H.E. 100x
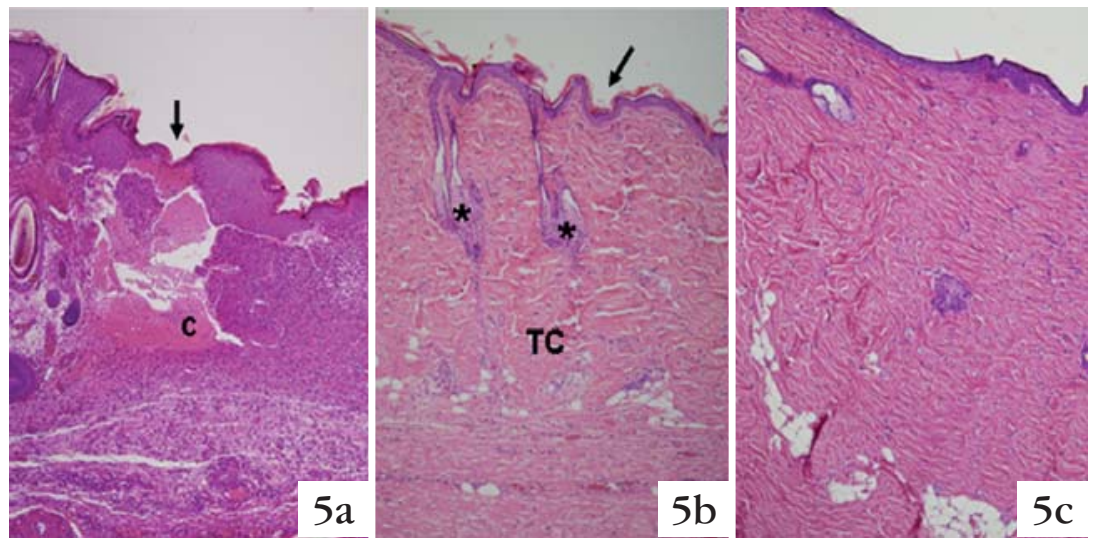

FIGURA 5: Grupo II: A. 7 dias: observa-se presença de coágulo sangüíneo (c), reação inflamatória de leve a moderada, no tecido conjuntivo, o epitélio não apresenta superfície de continuidade (seta). H.E. 100x; B. 30 dias: o epitélio apresenta superfície de continuidade, com presença de células querato-hialínicas na superfície (seta), tecido conjuntivo, organizado com fibras colágenas mais densas (TC), e folículos pilosos (*). H.E. 100x; C. 120 dias: tecido conjuntivo fibroso com características de normalidade. H.E. 100x.

so queratinizado apresentou-se em reorganização, com ausência de solução de continuidade na superfície e presença de tecido necrótico, acima da ferida. $\mathrm{O}$ tecido subjacente também se apresentou desorganizado, com poucas células inflamatórias, como: monócito e linfócitos e um grande número de fibroblastos e material remanescente englobado por algumas células gigantes (Figura 6A). No período de 30 dias, observou-se tecido epitelial reparado, também apresentando solução de continuidade com células querato-hialínicas, e o tecido conjuntivo apresentando-se denso e fibroso, com características de normalidade, com maior quantidade de fibras colágenas espessas e compactas, em relação ao tecido conjuntivo adjacente, os quais possuem uma organização de feixes não-definida, semelhante ao grupo I. Ausência de material remanescente e de células inflamatórias. (Figura 6B). Aos 120 dias, as fibras colágenas também se tornaram mais densas e fibrosas, com reorganização mais uniforme que o tecido conjuntivo adjacente, principalmente, próximo à lâmina própria, onde se observam ductos glandulares, folículos pilosos e capilares no tecido conjuntivo reparado (Figura 6C).

\section{DISCUSSÃO}

Os derivados de cianoacrilatos não substituem as suturas, mas oferecem uma alternativa à síntese tecidual em determinadas situações. Em ferimentos cutâneos, tais como: incisões ou lacerações, possibilitam aposição das bordas do ferimento, sem necessidade de curativos oclusivos. Atualmente, cirurgiões plásticos têm usado-os, em múltiplas situações, principalmente, em procedimentos de cirurgias cosméticas, ${ }^{12}$ em pequenos cortes ou em reaproximação de lacerações, com suporte de suturas. ${ }^{27}$

No presente estudo, durante a síntese tecidual, com ambos adesivos etil-cianoacrilato (Super Bonder ${ }^{\circledR}$ ) e butil-cianoacrilato (Histoacryl ${ }^{\circledR}$ ), pôde-se observar o efeito hemostático imediato e eficaz, quando comparado à sutura convencional. o Histoacryl ${ }^{\circledR}$ promoveu um efeito hemostático mais eficaz, em relação ao Super Bonder, ${ }^{\circledR}$ e esta característica pode decorrer, em função de o Histoacryl ${ }^{\circledR}$ ser mais fluído, o que permite um melhor escoamento sobre a superfície tecidual, no local da ferida, promovendo um efeito hemostático, em maior intensidade, ou ainda, quando a cadeia lateral, com quatro carbonos, faz com que o adesivo seja mais eficaz como agente 

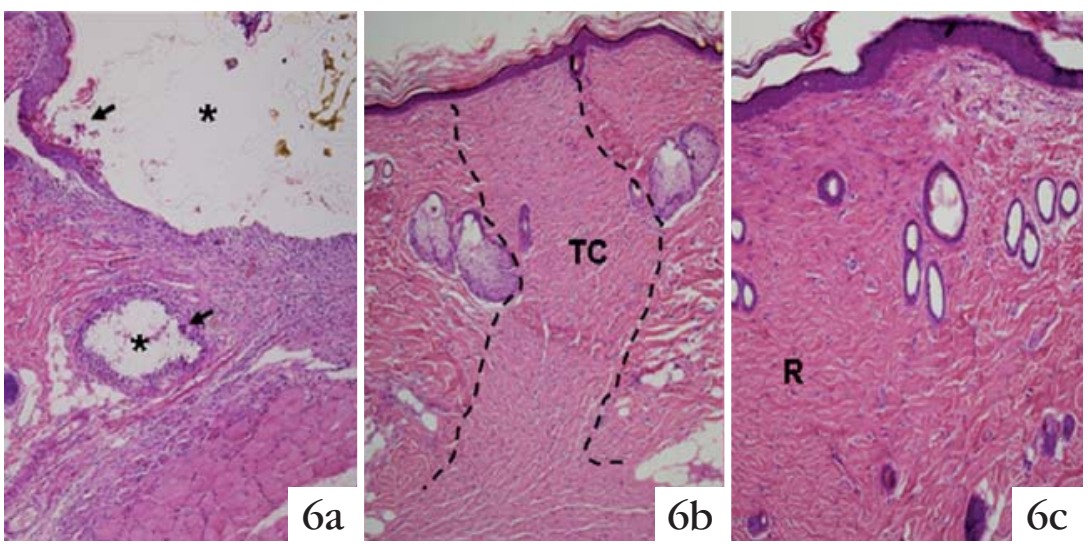

Figura 6: Grupo III: A. -7 dias: epitélio estratificado pavimentoso queratinizado com ausência de solução de continuidade na superfície. Observamse poucas células inflamatórias, no tecido conjuntivo frouxo adjacente ao adesivo, presença de macrófagos (setas) e material remanescente $\left(^{*}\right)$. H.E. 100x; B. 30 dias: reparação do epitélio estratificado pavimentoso queratinizado, com solução de continuidade na superfície (seta); no local na incisão, o tecido conjuntivo apresenta-se mais denso, fibroso e em organização (TC). H.E. 100x; C. 120 dias: observam-se fibras colágenas densas e organizadas no local do tecido reparado (R). H.E. $100 \mathrm{x}$

hemostático. Na literatura, não há nenhum dado que relata a razão entre as diferenças do efeito hemostático, proporcionado pelos diferentes adesivos à base de cianoacrilato. Somente relatam que estes adesivos proporcionam um efeito hemostático imediato, se comparado à técnica de sutura convencional.2, 3, 8

Reação tipo corpo estranho foi observada, adjacente aos adesivos Super Bonder ${ }^{\circledR}$ e Histoacryl ${ }^{\circledR}$ e ao tubo de polietileno (controle), nos grupo A e B, sendo observada em todos os espécimes nos períodos de 7 e 30 dias, com presença de inúmeras células gigantes, principalmente, ao redor dos adesivos. Após 120 (cento e vinte) dias, a quantidade de células gigantes diminuiu e podem-se observar apenas algumas células gigantes, adjacentes aos adesivos e ao tubo. Entretanto, quando esses adesivos estão englobados pelo tecido conjuntivo, em pequenas quantidades, durante a reparação da síntese das incisões, não foi observada a presença de células gigantes, tipo corpo estranho, em nenhum espécime dos períodos analisados. Em realidade, só confirma que esta reação de corpo estranho persistente até os 120 dias de pósoperatório, nos espécimes do grupo A e B, e deve-se também ao tubo de polietileno, pois o tubo promoveu esse tipo de reação. Em relação às células gigantes ao redor dos adesivos Super Bonder ${ }^{\circledR} \mathrm{e}$ Histoacryl, ${ }^{\circledR}$ estas possuem a função de fagocitar o material remanescente, ou seja, a eliminação completa e tardia do adesivo é realizada por meio de reação de corpo estranho. 3 Desta forma, a quantidade de células gigantes está diretamente relacionada à quantidade de material presente nos tecidos. Os resultados descritos com Super Bonder ${ }^{\circledR}$ e o Histoacryl ${ }^{\circledR}$ corroboram aos dados da literatura, quando são utilizados estes adesivos, sendo que a reação de corpo estranho só foi observada, também, quando há persistência do material remanescente adjacente a tecidos ricamente vascularizados, ${ }^{12,} 28$ pois, quando o adesivo é eliminado entre os primeiros 7 dias de pós-operatório, não se observou a reação de corpo estranho, nos tecidos circundantes ao adesivo tecidual. $2,8,18,29$ Segundo Gonzalez et al., 30 os riscos de reação de corpo estranho e infecção são reduzidos, graças à biocompatibilidade e ao efeito bacteriostático dos cianoacrilatos, respectivamente.

No local da síntese das incisões, com ambos adesivos teciduais, o processo de reação inflamatória decorreu, de forma leve, nos primeiros sete dias; o fio de sutura promoveu uma reação inflamatória de leve a moderada. Esta reação inflamatória mais intensa, observada com a sutura, pode ocorrer, por conta de um trauma cirúrgico, decorrente da penetração da agulha e do fio de sutura, nos tecidos, representando fatores de: agressão e irritação adicionais, evidenciados pela maior intensidade de reação inflamatória. Após 30 dias, não se observaram mais células inflamatórias, como: monócitos, linfócitos e basófilos, nos tecidos reparados, tanto onde foram empregados os adesivos quanto o fio de sutura. Segundo Weber e Chapman ${ }^{13}$ e Toriumi et al., ${ }^{12}$ quanto menor fosse a cadeia do éster, maior seria sua histotoxicidade, porque a sua degradação tornou-se mais rápida. Contudo, observamos que o Super Bonder ${ }^{\circledR}$ não provocou, em nenhum período, reação inflamatória, em maior intensidade, que o Histoacryl, ${ }^{\circledR}$ nos espécimes, onde se realizou a coaptação das margens da incisão. Corroborando aos resultados de Santos et al. ${ }^{26}$ e Souza et al.. ${ }^{31}$ que utilizaram Super Bonder ${ }^{\circledR}$ e sutura para coaptação de incisões, em dorso de rato, e observaram que o adesivo foi menos agressivo que a sutura. Quando utilizado Histoacryl ${ }^{\circledR}$ para coaptação de incisões, em dorso de porco, também se observou que este adesivo não promoveu inflamação, em relação à sutura. ${ }^{8}$

Nos espécimes onde se implantaram os tubos de polietileno, com os respectivos adesivos, em tecido ricamente vascularizado, a reação inflamatória persistiu até 120 dias, nos grupo A e B, e, sendo mais inten- 
sa, no grupo B, do Histoacryl, ${ }^{\circledR}$ provavelmente, graças à maior quantidade de remanescente de material, e sua degradação ter sido mais lenta, o que promoveu uma reação inflamatória maior, em relação ao grupo A, Super Bonder. ${ }^{\circledR}$ Por outro lado, há trabalhos que relatam que os cianoacrilatos, em contato com tecido ricamente vascularizado, promovem uma reação inflamatória mais intensa do que, quando em contato em tecidos, tais como, osso e cartilagem. ${ }^{12,} 29$ Por conta de a maior vascularização, os produtos liberados, durante a degradação (cianoacetato e formaldeído) ficam mais expostos à vascularização, levando a uma resposta inflamatória maior. Pois, quando se realiza a síntese de lacerações, feridas ou incisões de pequena profundidade com cianoacrilato, estes não desenvolvem reação inflamatória.8, 26 Resultados semelhantes aos observados por outros pesquisadores, quando utilizaram etilcianoacrilato, em tecido ósseo, $18,29,30$ em dorso de animais, 26,31 ou quando utilizaram butil-cianoacrilato, em dorso, ${ }^{3,}, 8$ em tecido ósseo, ${ }^{14}$ mostrando que o Super Bonder ${ }^{\circledR} \mathrm{e}$ o Histoacryl ${ }^{\circledR}$ são biocompatíveis às estruturas analisadas.

A utilização desses adesivos, porém, se limita a fechamento de lacerações e incisões, em áreas de baixa tensão, pois proporciona uma resistência à tensão, inferior à sutura convencional. O butil-cianoacrilato $^{32}$ e o octil-cianoacrilato, ${ }^{33}$ se comparados ao fio de sutura 5-0, apresentaram uma resistência à tensão, semelhante ao fio de sutura. Os cianoacrilatos somente são eficazes em feridas profundas, até que estes

\section{REFERÊNCIAS}

1. Mattick A. Use of tissue adhesives in the management of pediatric lacerations. Emerg Med J. 2002; 19:382-5.

2. Saska S, Minarelli-Gaspar AM. Análise comparative na coaptação de tecido periodontal entre adesivo à base de cianoacrilato (Super Bonder) e fio de sutura. Rev FOA. 2006;8:7-9.

3. Pérez M, Fernández I, Márquez D, Bretaña RMG. Use of n-butyl-2-cyanoacrylate in oral surgery: biological and clinical evaluation. Artif Organs. 2000;24:241-43.

4. Al-Belasy FA, Amer MZ. Hemostatic effect of n-butyl-2-cyanoacrylate (histoacryl) glue in warfarin-treated patients undergoing oral surgery. J Oral Maxillofac Surg. 2003;61:1405-09.

5. Döner F, Sari I. Facial wound closure with butyl estejam associados a suturas subcutâneas, 34 embora, quando há uma ferida, em regiões de baixa tensão, os adesivos de cianoacrilato são os materiais de escolha para este tipo de síntese.

Os adesivos de cianoacrilatos, como Super Bonder ${ }^{\circledR}$ e Histoacryl ${ }^{\circledR}$, apresentam inúmeras vantagens, a saber: resultados cosméticos aceitáveis, ausência de complicações, custo-benefício, a considerar (principalmente quando se trata com Super Bonder ${ }^{\circledR}$ ), não necessitam de anestesia local para realização do procedimento de coaptação, não há necessidade de remoção de sutura (dentro de 5 a 10 dias são eliminados), servem como barreira contra penetração de microrganismos, ${ }^{22,} 33$ além do tempo operatório ser menor, em relação à sutura convencional. ${ }^{3,8}$

\section{CONCLUSÕES}

Com base na metodologia empregada, concluímos que os adesivos Super Bonder ${ }^{\circledR}$ e Histoacryl, ${ }^{\circledR}$ se usados para síntese de tecido mole, permitem o processo cicatricial dos tecidos incisados, sem promover reação inflamatória. Além disso, os adesivos facilitam a coaptação das margens incisadas, reduzindo o tempo do procedimento cirúrgico, em relação ao fio de sutura. O adesivo Super Bonder ${ }^{\circledR}$ promoveu uma reação inflamatória de menor intensidade que o Histoacryl, ${ }^{\circledR}$ em subcutâneo de ratos, bem como estes adesivos não promoveram necrose tecidual. Portanto, os adesivos de cianoacrilatos podem ser utilizados para sínteses de feridas, lacerações ou incisões cutâneas. 2-cyanoacrylate. J Basic Clin Physiol Pharmacol. 2003;14:359-71.

6. Camacho-Alonso F, Lopez-Jornet P, BermejoFenoll A. Effects of scalpel (with and without tissue adhesive) and cryosurgery on wound healing in rat tongues. Oral Surg Oral Med Oral Pathol Radiol Endod. 2005; 100:58-63.

7. Turkaslan T, Ozcan H, Dayicioglu D, Ozsoy Z. Use of adhesives in cleft palate surgery: a new flap fixation technique. J Craniofac Surg. 2005;16:719-22.

8. Giray CB, Sungur A, Atasever A, Araz K. Comparasion of silk sutures and n-butyl-2-cyanoacrylate on the healing of skin wounds. A pilot study. Aust Dent J. 1995;40:43-5.

9. Reece TB, Maxey TS, Kron IL. A prospectus on tissue adhesives. Am J Surg. 2001;182:40S-4S. 
10. Ardis AE. U.S. Patents No. 2467926 and 2467927(1949).

11. Coover HW, Joyner FB, Shearer Jr NH, Wicker Jr TH. Chemistry and performance of cyanoacrylate adhesive. J Soc Plast Eng. 1959;15:413-17.

12. Toriumi DM, Raslan WF, Friedman M, Tardy E. Histotoxicity of cyanoacrylate tissue adhesives. A comparative study. Arch Otolaryngol Head Neck Surg. 1990;116:546-50.

13. Weber SC, Chapman MW. Adhesives in orthopedic surgery a review of the literature and in vitro bonding strengths of bone-bonding agents. Clin Orthop. 1984;191249-56.

14. Shermak MA, Wong L, Inoue W, Crain BJ, Im MJ, Chao EY, et al. Fixation of the craniofacial skeleton with butyl-2-cyanoacrylate and its effect on histotoxicity and healing. Plast Reconstr Surg. 1998;102:309-18.

15. Thumwanit V, Kedjarune U. Cytotoxicity of polymerized commercial cyanoacrylate adhesive on cultured human oral fibroblasts. Australian Dent J. 1999; 44:248-52.

16. Kline DG, Hayes GJ. An experimental evaluation of the effect of a plastic adhesive methyl-2-cyanoacrylate on neural tissue. J Neurosurg. 1963;20:647-51.

17. Barreiro P, Ramirez JFS, Lopez ED. Experiência em 10 casos de sutura cutânea usando el adhesivo etil-cianoacrilato. Ginec Obst Mex. 1995;63:10-4.

18. Saska S, Roslindo EB, Bolini PDA, MinarelliGaspar AM. Uso do adesivo à base de etil-cianoacrilato na reparação óssea. Rev Bras Ortop. 2004;39:461-67.

19. Aksoy M, Turnadere E, Ayalp K, Kayabali M, Ertugrul B, Bilgic L. Cyanoacrylate for wound closure in prosthetic vascular graft surgery to prevent infections through contamination. Surg Today. 2006;36:52-6.

20. Ellis DA, Shaikh A. The ideal tissue adhesive in facial plastic and reconstructive surgery. J Otolarygol. 1990;19:68-72.

21. Craven NM, Telfer NR. An open study of tissue adhesive in full-thickness skin grafting. J Am Acad Dermatol. 1999;40:607-11.

22. Goktas N, Karcioglu O, Coskun F, Karaduman $\mathrm{S}$, Menderes A. Comparison of tissue adhesive and suturing in the repair of lacerations in the emergency department. Eur J Emerg Med. 2002; 9:155-8.

23. Pelissier P, Casoli V, Le Bail B, Martin D, Baudet J. Internal use of n-butyl 2-cyanoacrylate (Indermil) for wound closure: an experimental study. Plast Reconstr Surg. 2001;108:1661-6.
24. Kulkarni SS, Chava VK. Comparison of cyanoacrylate and silk sutures on healing of oral wounds- an animal model study. Indian J Dent Res.

2003; 14:254-8.

25. Vanholder R, Misotten A, Roels H, Matton G. Cyanoacrylate tissue adhesive for closing skin wounds: a double blind randomized comparison with sutures. Biomaterials. 1993;14:737-42.

26. Santos GM, Lacaz Netto R, Santos LM, Okamoto T, Rocha RF. Uso do Super Bonder no reparo das feridas cirúrgicas. RGO. 1990;38:435-39.

27. Zempsky WT, Parrotti D, Grem C, Nichols J. Randomized controlled comparison of cosmetic outcomes of simple facial lacerations closed with Steri Strips skin closures or Dermabond tissue adhesive. Pediatric Emerg Care. 2004;20:519-24.

28. Choi HB, Kim BY, Huh JY, Lee SH, Zhu SJ, Jung $\mathrm{JH}$, et al. Microneural anastomosis using cyanoacrylate adhesives. Int $\mathrm{J}$ Oral Maxillofac Surg. 2004;33:777-80.

29. Caroli A, Marcuzzi A, Limontini S, Maiorana A. An experimental study of a cyanoacrylate biological adhesive in view of its use in the fixation of various fractures of the fingers. Ann Chir Main Memb Super. 1997;16:138-45.

30. Gonzalez E, Orta J, Niemshik L, Galera R, Onay R, Rojas O. Ethyl-2-cyanoacrylate fixation of the cranial bone flap after craniotomy. Surg Neurol. 2000;53:288-89.

31. Souza SC, Oliveira WL, Soares DFOS, Briglia CH, Athanázio PA, Cerqueira MD, et al. Comparative study of suture and cyanoacrylates in skin closure of rats. Acta Cir Bras. 2007;22:309- 16.

32. Noordzij JP, Foresman PA, Rodeheaver GT, Quinn JV, Edlich RF. Tissue adhesive wound repair revisited. J Emerg Med. 1994;12:654-9.

33. Singer AJ, Thode Jr., HC. A review of the literature on octylcyanoacrylate tissue adhesive. Am J Surg. 2004; 187:238-48.

34. Bresnahan KA, Howell JM, Wizorek J. Comparison of tensile strength of cyanoacrylate tissue adhesive closure of lacerations versus suture closure. Ann Emerg Med. 1995;26:575-8.

\footnotetext{
ENDEREÇO PARA CORRESPONDÊNCIA / MAILING ADDRESS:

Sybele Saska

Rua Humaitá, 1680 - Araraquara

14.803901 São Paulo

Faculdade de Odontologia de Araraquara - UNESP

Departamento de Morfologia.

Tel./Fax: 1633016492 / $3301-6600$ ramal: 6765

E-mail:sybele_saska@yaboo.com.br
}

Como citar este artigo / How to cite this article: Saska S, Gaspar AMM, Hochuli-Vieira E. Adesivos à base de cianoacrilato para síntese de tecido mole. An Bras Dermatol. 2009;84(6):595-92. 